\title{
Between the distortion and the gradience: Deaf perception of Brazilian Sign Language Hand Shapes
}

Felipe Venâncio Barbosa ${ }^{1}$, Janice Gonçalves Temoteo ${ }^{1}$, Roberta Silvestre ${ }^{1}$, Antonieli Cantarelli ${ }^{2}$

${ }^{1}$ Department of Linguistics, University of São Paulo, Brazil

${ }^{2}$ Institute of Psychology, University of São Paulo, Brazil

https://doi.org/10.36505/ExLing-2015/06/0004/000241

\begin{abstract}
This study aims observe whether/how Libras Deaf users realize distortions in HS during a Libras' sign accomplishment and whether the hand proximity to the face can influence the perception. A group of deaf signers analyzed a video recorded with signs of Brazilian Sign Language (Libras) performed in two groups: a group of 10 with hands near to the face and far from the face, with three performances, one with the correct sign, one with a slight alteration in finger selection of HS and one distorted. The results suggest that distortion is perceived as a inappropriate expression of a isolated sign. The significant difference between signs with mild distortion near to the face and far from the face can indicate that the linguistic information provided for the face are competitive stimuli and for this reason may inhibit the perception of mild distortions near to the face but may not inhibit the perception of distortions when it is accomplished in a Location without competitive stimuli.
\end{abstract}

Key words: Brazilian Sign Language, Phonetic-Phonological Analysis, Distortion, Gradience N

\section{Introduction}

Hand-Shapes (HS), Location, Movement, Hand Orientation and Non Manual Expressions are described as items that build the internal structure of lexical items in sign languages: the sign (Ferreira-Brito 1995, Quadros e Karnopp 2004, Xavier 2006). In the case of HS, the sort of fingers selection defines specific configurations that compose the sign. Some of these HS are contrastive and delimit minimal pairs in Brazilian Sign Language (Libras). However, the HS accomplishment may present distortions that can be seen as gradient or as errors. The understanding of the accomplishment of phonetic-phonological items in sign language and its perception can bring information about the linguistic processing itself and can give useful information to applied linguistics, mainly in interface areas as speech therapy and neurolinguistics.

This study aims observe whether/how Libras Deaf users realize distortions in HS during a Libras' sign accomplishment and whether the hand proximity to the face can influence the perception.

ExLing 2015: Proceedings of 6th Tutorial and Research Workshop on Experimental Linguistics, 26-27 June 2015, Athens, Greece 


\section{Methods}

To this end, a video was recorded with an informant performing 19 signs of Libras in two groups: a group of 10 with hands near to the face and a group of 9 signs with hands far from the face. Each sign was accomplished three times, one (correct sign) according to the New Trilingual Illustrated Encyclopaedic Dictionary of Brazilian Sign Language (Capovilla, Raphael, \& Mauricio, 2009), one (slight distortion) with alterations in finger selection of HS and one (distorted) with great alteration in the finger selection, totalizing 57 presentations. The videos were presented randomly avoiding the sequence of the same signs in the possibilities presented (correct, slight distortion, distorted). Fourteen Deaf informants saw the signs and presented an assessment in a 0 to 10 scale, with marks near to zero to wrong signs and near to ten for correct signs, for each sign.

\section{Results and Discussion}

The responses given in the scales were quantified and the data were analyzed using the ANOVA test to compare the three gradients for each location as well as all of them together (General).

Table 1: Compares Gradients for each Location.

\begin{tabular}{|c|c|c|c|c|c|c|c|c|}
\hline Gradient & & Mean & Median & $\begin{array}{l}\text { Standard } \\
\text { Deviation }\end{array}$ & $\mathrm{VC}$ & $\mathrm{N}$ & CI & P-value \\
\hline \multirow{3}{*}{ Far from the Face } & Correct & 7.74 & 10 & 3.28 & $42 \%$ & 126 & 0.57 & \multirow{3}{*}{$<0,001$} \\
\hline & Distorted & 4.45 & 4 & 3.58 & $80 \%$ & 126 & 0.62 & \\
\hline & Slight & 4.22 & 3 & 3.86 & $91 \%$ & 126 & 0.67 & \\
\hline \multirow{3}{*}{ Near the Face } & Correct & 8.27 & 10 & 3.05 & $37 \%$ & 140 & 0.51 & \multirow{3}{*}{$<0,001$} \\
\hline & Distorted & 4.29 & 3 & 3.60 & $84 \%$ & 140 & 0.60 & \\
\hline & Slight & 6.31 & 8 & 3.98 & $63 \%$ & 140 & 0.66 & \\
\hline \multirow{3}{*}{ General } & Correct & 8.02 & 10 & 3.17 & $39 \%$ & 266 & 0.38 & \multirow{3}{*}{$<0,001$} \\
\hline & Distorted & 4.36 & 3,5 & 3.58 & $82 \%$ & 266 & 0.43 & \\
\hline & Slight & 5.32 & 5 & 4.05 & $76 \%$ & 266 & 0.49 & \\
\hline
\end{tabular}

Table 2: P-values from Table 1.

\begin{tabular}{llll}
\hline \hline & & Correct & Distorted \\
\hline \multirow{2}{*}{ Far from the Face } & Distorted & $<0.001$ & \\
\cline { 2 - 4 } & Slight & $<0.001$ & 0.651 \\
\hline \multirow{3}{*}{ Near the Face } & Distorted & $<0.001$ & \\
\cline { 2 - 4 } & Slight & $<0.001$ & $<0.001$ \\
\hline & Distorted & $<0.001$ & \\
\cline { 2 - 4 } & Slight & $<0.001$ & 0.004 \\
\hline
\end{tabular}


Defining the significance level in 5\%, results show that the Deaf informants can identify the correct signs and can differentiate it from signs distorted and with slight distortion, with mean scores presenting significant difference $(p<0,001)$, as both group of signs near to the face and signs far from the face. The difference between the general means of signs with mild distortion and signs distorted are statistically significant $(\mathrm{p}=0,004)$, however signs with mild distortion accomplished near to the face do not present significant difference when compared with distorted signs $(\mathrm{p}=0,651)$. The difference between signs with mild distortion and distorted is significant when accomplished far from the face $(p<0,001)$. The distortion in the fingers selection on HS is identified as inappropriate, although the informant can understand the sign since the HS was distorted and not changed.

We used the same test to compare the two locations in each Gradient. The results shown that there are only significant statistical mean differences among the locations for the Slight Gradient, where we observed a mean of 4.22 for far from the face compared to 6.31 for near the face ( $\mathrm{p}$-value <0001).

Table 3: Compares Locations in each Gradient

\begin{tabular}{lllllllll}
\hline \hline Location & & Mean & Median & SD & VC & N & CI & P-value \\
\hline \multirow{2}{*}{ Correct } & Far & 7.74 & 10 & 3.28 & $42 \%$ & 126 & 0.57 & \multirow{2}{*}{0.170} \\
\cline { 2 - 9 } & Near & 8.27 & 10 & 3.05 & $37 \%$ & 140 & 0.51 & \\
\hline \multirow{2}{*}{ Distorted } & Far & 4.45 & 4 & 3.58 & $80 \%$ & 126 & 0.62 & \multirow{2}{*}{0.705} \\
\cline { 2 - 9 } Slight & Near & 4.29 & 3 & 3.60 & $84 \%$ & 140 & 0.60 & \\
\cline { 2 - 9 } & Far & 4.22 & 3 & 3.86 & $91 \%$ & 126 & 0.67 & $<0.001$ \\
\hline \hline
\end{tabular}

The significant difference between signs with mild distortion near to the face and far from the face can indicate that the linguistic information provided for the face are competitive stimuli and for this reason may inhibit the perception of mild distortions near to the face but may not inhibit the perception of distortions when it is accomplished in a Location without competitive stimuli.

\section{Conclusions}

The results suggest that distortion is perceived as an inappropriate expression of an isolated sign and it was characterized as a distortion and not as gradient. The significant difference between signs with mild distortion near to the face and far from the face can indicate that the linguistic information provided for the face are competitive stimuli and for this reason may inhibit the perception of mild distortions near to the face but may not inhibit the perception of distortions when it is accomplished in a Location without competitive stimuli. 
16 F.V. Barbosa, J.G. Temoteo, R. Silvestre, A. Cantarelli

\section{References}

Capovilla, FC, Raphael, WD, Maurício, ACL. 2009. New Trilingual Illustrated Encyclopaedic Dictionary of Brazilian Sign Language. São Paulo. Edusp.

Ferreira-Brito, L. 1995. Por uma gramática da Língua de Sinais. Rio de Janeiro: Editora Tempo Brasileiro.

Quadros, RM, Karnopp, LB. 2004. Língua de Sinais Brasileira - estudos lingüísticos. Porto Alegre: ArtMed.

Xavier, AN. 2006. Descrição fonético-fonológica dos sinais da língua de sinais brasileira. Dissertação de mestrado. São Paulo, USP. 